\title{
Egg Development and Morphology of Larva and Juvenile of the Oryzias latipes
}

\author{
Sung-Hun Lee ${ }^{1}$, Chun-Cheol Kim ${ }^{2}$, Soo-Jin Koh ${ }^{1}$, Lim-Soo Shin ${ }^{1}$, \\ Jae-Kwon $\mathrm{Cho}^{3}$ and ${ }^{\dagger}$ Kyeong-Ho Han ${ }^{1}$ \\ ${ }^{1}$ Aquaculture Program, College of Fisheries and Ocean Sciences, Chonnam National University, \\ Chonnam 550-749, Korea \\ ${ }^{2}$ Inland Fisheries Research Laboratory, Jeollanamdo Provincial Government, Jangsung 520-854, Korea \\ ${ }^{3}$ Southwest Sea Fisheries Research Institute, NFRDI, Yeosu 556-823, Korea
}

\begin{abstract}
In order to monitor the developmental features of embryos, larvae, and juveniles of Oryzias latipes (Temminck and Schlegel), Oryzias latipes was caught in river of Shinduck-dong, Yeosu-si, Jeollanam-do, on May 2011, and experiments were carried out in Ichthyology laboratory at Chonnam National University. The blastodisc step was the first level for natural spawning. The optic vesicle, Kupffer's vesicle, myotome began to appear 75 hours 57 minutes later. After blastodisc development, the pectoral fins were made at 143 hours 37 minutes and the tail was separated started at the same time. Hatching was observed at 167 hours 27 minutes after blastodisc. The total length of the hatched larvae was 4.95 5.10 mm (mean, 5.01 mm), the mouth and anus were opened. Larvae used yolk completely after 3 days after hatching. The total length larvae was 5.45 5.56 mm (mean, $5.52 \mathrm{~mm}$ ) after 8 days after hatching, and appeared the stems for tail. The stems pectoral, anal fin were showed after 14 days and the stems dorsal, ventral fin were appeared after 19 days. For 35 days after hatching, the total length of larvae $13.95 \sim 15.30 \mathrm{~mm}$ (mean, $14.64 \mathrm{~mm}$ ), and at this time, fins and body were transferred like the adult Oryzias latipes.
\end{abstract}

Key words : Oryzias latipes, Egg, Larva, Juvenile, Hatched

\section{INTRODUCTION}

Oryzias latipes belongs to the order of Beloniformes and Adrianichthyidae, and is known to be distributed in Japan, China, and Korea. In South Korea, Oryzias latipes are often found in freshwater areas (e.g., Nakdong-river as well as other rivers flow into the East Sea) yet they are also discovered around brackishwater areas.

Oryzias latipes are characterized with 1) small size, 2) short generation, 3) high resistance against water temperature, salinity, water quality, pollution, and oxygen content, and 4) ease of laboratory breeding hence they are widely utilized for study purposes such as genetics, physiology, and development researches (Kim \& Kim, 1993).

There are several domestic/international studies investigated regarding taxonomy and distribution of Oryzias latipes in the Yunnan region of China (Chen et al., 1989), distribution areas and karyotypes of indian Oryzias latipes (Uwa, 1986), coefficient/measuring characteristics, and karyotypes of Oryzias latipes found in Southern/island areas of South

\footnotetext{
Manuscript received 14 August 2014, Received in revised form 22 August 2014, Accepted 29 August 2014

${ }^{\dagger}$ Corresponding Author : Kyeong-Ho Han, 707 College of Fisheris and Ocean Sciences, Chonnam National University, 50 Daehak-ro, Yeosu-si, 550-749, Korea. Tel. : +82-61-659-3163, Fax : +82-61-655-0244, E-mail : aqua05@jnu.ac.kr

This is an Open Access article distributed under the terms of the Creative Commons Attribution Non-Commercial License (http:// creativecommons.org/licenses/by-nc/3.0) which permits unrestricted non-commercial use, distribution, and reproduction in any medium, provided the original work is properly cited.
} 
Korea (Kim \& Moon, 1987; Magtoon \& Uwa, 1985; Uwa $\&$ Jeon, 1987), chromosomes of Oryzias latipes (Levan et al., 1964), two distinct population of Korean Oryzias latipes (Sakaizumi \& Jeon, 1987), and list of subspecies for novel Korean Oryzias latipes sinensis (Kim \& Lee, 1992); however there is scant investigation in reference to spawning habits as well as developmental characteristics of larvae and juvenile Oryzias latipes.

In the present, therefore, the authors investiaged the morphology of larvae and juvenile Oryzias latipes in their egg development and growth phases as a part of basic biological studies for the development of ornamental fishes, protection of Oryzias latipes, and to provide preliminary data for taxonomic studies.

\section{MATERIALS AND METHODS}

Adult Oryzias latipes and eggs laid on weeds were collected from a river in Shinduck-dong, Yeosu-si, Jeollanamdo utilizing skimming nets (mesh, $5.5 \mathrm{~mm}$ ) and dredge from May 2011 (Fig. 1). Collected eggs were observed using a universal projector for egg sizes (i.e., the diameter of eggs) while their morphological traits were investigated with a stereoscopic microscope.

Hatched larvae were subsequently fed with water flea and feeding stuff for fish culture in the glass water tank $(30 \times 50 \times 30 \mathrm{~cm})$ while the temperature was maintaining 20.0 $25.4^{\circ} \mathrm{C}$ (average $23.0^{\circ} \mathrm{C}$ ); rearing water was daily changed (morning and afternoon; 1/2 per each time, respectively). In order to monitor morphological development of larvae and juvenile Oryzias latipes, each part of body was observed and measured utilizing the stereoscopic microscope and universal projector from hatching to 35 days after hatching; in each day, an average of ten fishes was anesthetized with ice and MS-222 Sandoz (Tricaine methane sulfonate) for measurements and developmental stages were determined as described elsewhere Russell (1976).

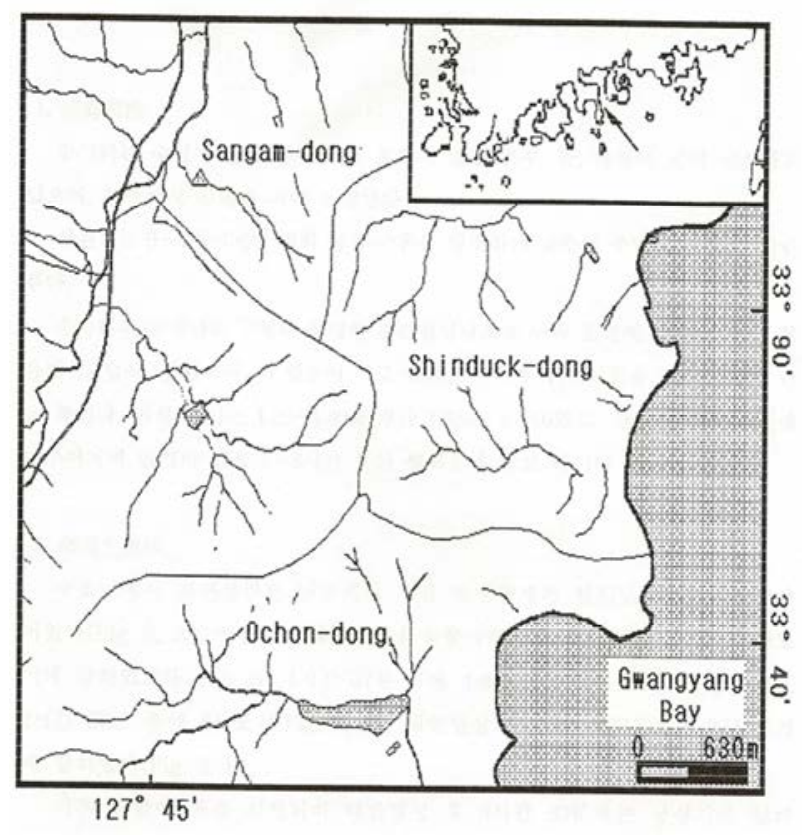

Fig. 1. Map showing the sampling stations in stations in the Shin-duck, Yeosu.

\section{RESULTS}

\section{Developmental stages of eggs}

The earliest event for naturally hatched eggs was the formation of blastodisc was observed (Fig. 2, A). After the formation of blastodisc, the cleavage was initiated from the germinal pole at 47 minutes (Fig. 2, B), and subsequently reached to the 4-cell stage at 1 hour 37 minutes (Fig. 2, C). The embryo reached at 8-cell stage and 32-cell stage after 2 hours 27 minutes and 3 hours 27 minutes of the blastodisc formation (Fig. 2, E). As the cleavage progressing, the embryo reached the morula stage (Fig. 2, F) and blastula stage (Fig. 2, G) after 8 hours 39 minutes and 23 hours 37 minutes from the blastodisc, respectively. In turn, the embryo reached the gastrula stage after 32 hours 56 minutes (Fig. 2, H).

After 47 hours 22 minutes of the formation of blastodisc, an elongated embryo was formed on the side of york (Fig. 2, I), and then optic vesicle, kupffer's vesicle, and myotome were formed in the embryo at 75 hours 57 minutes (Fig. 2, J). The prototype of pectoral fin was form after 143 hours 37 




Fig. 2. Egg development of Oryzias latipes reared in the laboratory. A: Formation of blastodisc; B: 2 cells stage, 47 mins.; C: 4 cells stage, 3 hrs. 27 mins.; F: Morula stage, 8 hrs. 39 mins.; G: stage, 23 hrs. 37 mins.; H: Gastrula stage, 32 hrs. 56 mins.; I: Embryo formation, 47 hrs. 22 mins.; J: Formation of optic vesicle, 75 hrs. 57 mins.; K: Caudal part leaves york sac, 143 hrs. 37 mins.; L: Embryo just before hatching, $167 \mathrm{hrs.} 37$ mins.

minutes of blastodisc formation while the tail was split; in this, the embryo started to move intermittently (Fig. 2, K).

The embryo broke through the egg membrane and started to hatching from the head after 167 hours 27 minutes of formation of blastodisc (Fig. 2, L). The total length of hatched larvae was approximately $5.01 \mathrm{~mm}$ and swimming in a crowd near the bottom of water tank.

2. Morphological development of larva and juvenile Oryzias latipes
Right after hatching, the total length of larvae was 4.95 $5.10 \mathrm{~mm}$ (average $5.01 \mathrm{~mm}, n=10$ ) while both anus and mouth were opened. When hatched, most york was absorbed and the myotome was approximately 26 28 (8 9+18 19) and oil droplets were placed in the middle of the york; dorsal fin, anal fin and the caudal fin were connected via membranes and the prototype of caudal fin was observed.

Chromophores were slightly precipitated on eyes while melanophores were found on the upper part of head, back side of eyes, sides of embryo, and the air bladder with a shape of stars and dots. In this stage, larvae did not actively swim yet started to swim vigorously after 3 5 hours of hatching utilizing the caudal fin (Fig. 3, A).

3 days after hatching, the total length of larvae was around 5.25 5.53 mm (average $5.35 \mathrm{~mm}, n=10$ ) and active intake activities were observed; the york was completely absorbed and the fishes were shifted to the post-larvae stage. In this stage, as the gastrointestinal tract was being developed, the anus was placed on the position of approximately $40 \%$ of the total length and a little in front of the lateral side. While chromophores were precipitated on eyes, more melanophores were found on the head and air bladder; these were shown along with the lateral side with shapes of stars and dots. The caudal fin had three stems and the terminal notochord started to being bending (Fig. 3, B).

After 8 days of hatching, the post larvae had the total length of $5.45 \sim 5.60 \mathrm{~mm}$ (average $5.52 \mathrm{~mm}, n=30$ ) with eight stems formed on the caudal fin. On the front lateral side, chromophores were formed. (Fig. 3, C).

On the $14^{\text {th }}$ day from hatching, the post larvae represented the total length of $6.61 \sim 6.87 \mathrm{~mm}$ (average 6.73 $\mathrm{mm}, n=30$ ) while melanophores were getting more clear and obvious on the head as well as air bladder. The prototypes of pectoral fin and anal fin were shown, and rod-shaped bones on tail were developed (Fig. 3, D).

On the $19^{\text {th }}$ day from hatching, the total length of post- 

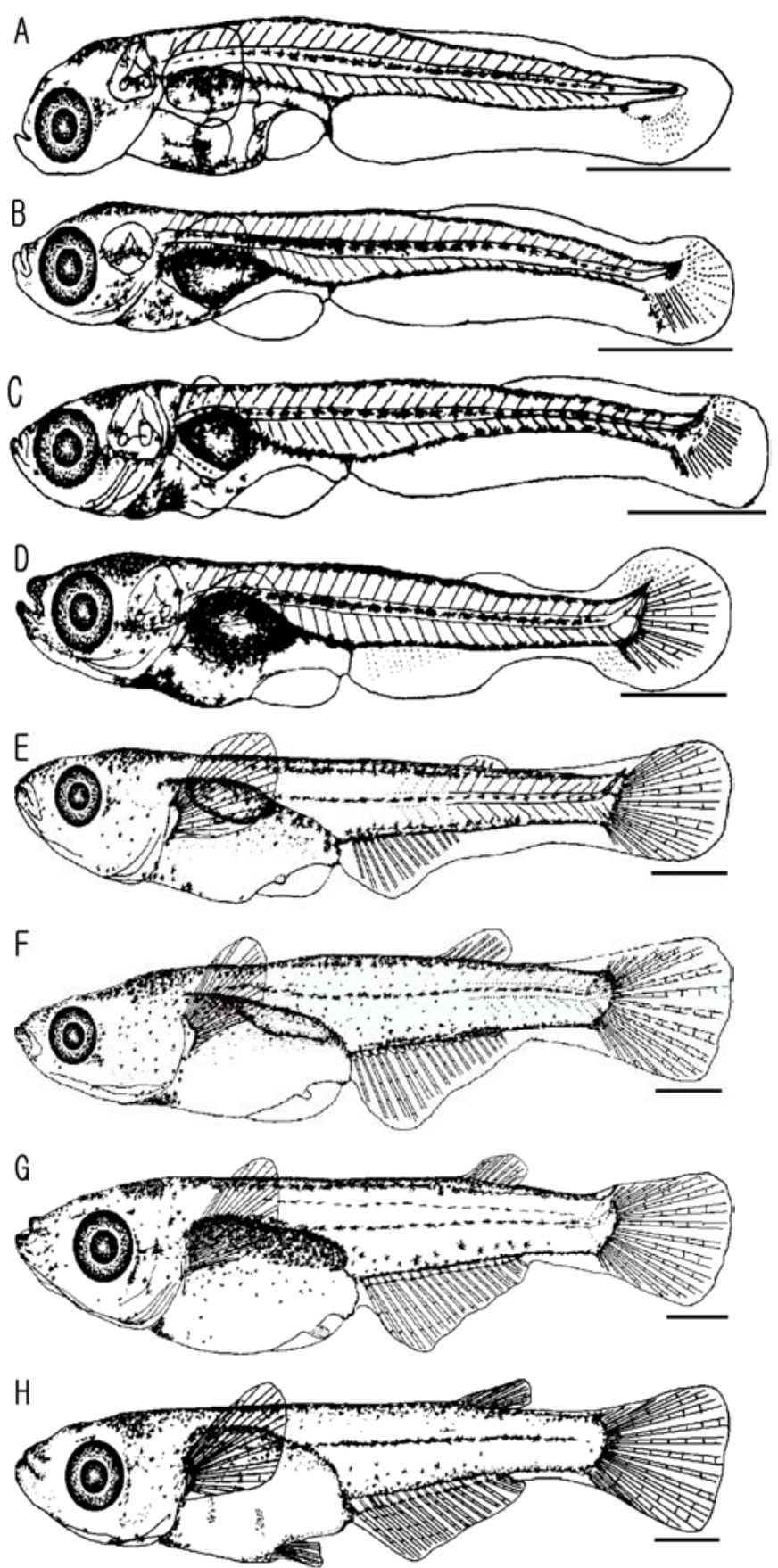

Fig. 3. The larvae and juveniles developmental stages of Oryzias latipes reared in the laboratory. A: Newly hatched prelarva, $5.01 \mathrm{~mm}$ in total length (TL); B: $5.35 \mathrm{~mm}$ in TL postlarva, 3 day after hatching; C: $5.52 \mathrm{~mm}$ in TL postlarva, 8 days after hatching; D: $6.73 \mathrm{~mm}$ in TL postlarva, 14 days after hatching; E: $9.51 \mathrm{~mm}$ in TL postlarva. 19 days after hatching; F: $11.58 \mathrm{~mm}$ in TL postlarva, 22 days after hatching; G: $12.47 \mathrm{~mm}$ in TL postlarva, 28 days after hatching; H: $14.64 \mathrm{~mm}$ in TL juvenile, 35 days after hatching. Scale bars indicate $1.00 \mathrm{~mm}$. larvae was $8.94 \sim 10.30 \mathrm{~mm}$ (average $9.51 \mathrm{~mm}, n=30$ ) and 3 stems on the dorsal fin were formed. The prototype was appeared on the ventral fin and melanophores were getting clearer along with the back side of fishes (Fig. 3, E).

After 22 days of hatching, the post larvae had the $10.81 \sim 12.80 \mathrm{~mm}$ of the total length (average $11.58 \mathrm{~mm}, n$ $=30$ ) and dorsal fin as well as anal fin were being formed; there were 6 7 stems of dorsal fin, 15 18 stems of anal fin, and 17 20 stems of caudal fin were formed (Fig. 3, F).

On the $28^{\text {th }}$ day from hatching, the total length of post larvae was $11.50 \sim 13.50 \mathrm{~mm}$ (average $12.47 \mathrm{~mm}, n=30$ ) and the ventral fin was being formed yet the primordial finfold was remained (Fig. 3, G).

After 35 days of hatching, the total length of the post larvae was 13.95 15.30 mm (average $14.64 \mathrm{~mm}, n=30$ ). All fins and numbers of fins were fixed, indicating that the juvenile stage was reached. The numbers of myotome were 32 34 (13 15+19 21) (Fig. 3, H).

\section{DISCUSSION}

When it comes to fish, morphological changes, observed in the development of larvae and juvenile fishes, have been widely utilized as important traits to identify classification such as family and genus (Okiyama, 1979).

Oryzias latipes is one of two fishes (the other is Oryzias sinensis) that belongs to the Oryzias genus; these fishes are very similar yet no study has been done in regards to their spawning habits and early life history.

Embryos of $O$. latipes are spherical transparent separate demersal eggs; there are short hairs as well as a bunch of long hairs on the membrane; these hairs stick together, working as sticking thread, thereby aiding to stick on weeds.

In the present study, the average size of $O$. latipes eggs was ranging 1.29 1.40 $\mathrm{mm}$ (average $1.35 \mathrm{~mm}, n=50$ ) which was slightly smaller than the observation of Kim \& Kim (1993) while bigger than those of O. latipes sinensis 
$(1.10 \sim 1.20 \mathrm{~mm}$, average $1.15 \mathrm{~mm})$. Also when it compares other freshwater fish, Zacco koreanus with $3.09 \pm 0.07 \mathrm{~mm}$ diameter (Lee et al., 2013) showed the big difference with O. sinensis, the egg size of Pseudogobio esocinus was $1.98 \pm 0.19 \mathrm{~mm}$ (Lee et al., 2008), the diameter of fertilized egg of Luciogobius grandis was $2.06 \pm 0.23 \mathrm{~mm}$ (Yun et al., 2008) so that egg diameter of was smaller than other freshwater fish. In comparison with the saltwater fish, Cinnamon Clownfish (Amphiprion melanopus)'s fertilized size was $2.4 \pm 0.1 \mathrm{~mm}$ (Noh et al., 2011), so there was no difference, and Scomber japonicus, otherwise, was smaller than $O$. latipes as the diameter $0.95 \pm 0.03 \mathrm{~mm}$ (Park et al., 2008).

On the other hand, we found that time took for hatching was approximately 167 hours 27 minutes from the formation of blastodisc; this results is somewhat different compared to other study. In the study of Kim \& Kim (1993), it took approximately 9 10 days for hatching and such inconsistency might be due to the difference in water temperature. The egg development of $Z$. koreanus was completed around 68 hours after fertilization (Lee et al., 2013), shown faster than $O$. latipes. The hatching time of $P$. esocinus was 164 hours (Lee et al., 2008), it was similar to $O$. latipes, and $L$. grandis was 120 hours 54 minutes (Yun et al., 2008), so it was earlier than $O$. latipes's hatching time. Cinnamon Clownfish (A. melanopus), saltwater aquarium fish, was 168 hours (Noh et al., 2011) and it was also similar to $O$. latipes, In saltwater fish case, the time for hatching of $S$. japonicus was far faster than O. latipes, as 51 hours (Park et al., 2008).

Right after the hatching, the total length of larvae was 4.95 5.10 mm (average $5.01 \mathrm{~mm}, n=10$ ) with opened anus and mouth. In the juvenile stage was reached after the 35 days from hatching; in this, the total length was found to be $14.64 \mathrm{~mm}$. Freshwater fish, Z. koreanus, the total length of larvae right after the hatching was $10.30 \pm 0.40 \mathrm{~mm}$, in the juvenile stage was reached after the 13 days from hatching as the total length $16.98 \pm 0.56 \mathrm{~mm}$ (Lee et al., 2013), it was faster than $O$. latipes. Total length of larvae of $P$. esocinus was $4.61 \pm 0.83 \mathrm{~mm}, 16.22 \pm 0.65 \mathrm{~mm}$ after the 42 days from hatching was reached in the juvenile stage (Lee et al., 2008). It showed similar to O. latipes, and L. grandis was $3.30 \pm 0.07 \mathrm{~mm}$ for larvae after hatching, $11.46 \pm 0.12 \mathrm{~mm}$ for juvenile after the 29 days (Yun et al., 2008). Saltwater aquarium fish, A. melanopus, showed larvae of average $3.5 \pm 0.3 \mathrm{~mm}$, it was developed like adult after the 90 days as $41.0 \pm 0.3 \mathrm{~mm}$ (Noh et al., 2011). The development was slower than $O$. latipes. In $S$. japonicus case, on the other hand, right after the hatching, the total length of larvae was average $2.75 \pm 0.04 \mathrm{~mm}$, in the juvenile stage was reached after the 25 days from hatching (average 55.95 $\pm 6.74 \mathrm{~mm}$ ) (Park et al., 2008), so that there was difference from $O$. latipes.

\section{REFERENCES}

Chen X, Uwa H, Chu X (1989) Taxonomy and distribution of the genus Oryzias in Yun-nan. China. Acta Zootaxononmica Sinica 14:239-246.

Joo CM, Jeon SR (1987) Two divergent groups in the wild populations of medaka Oryzias latipes in Korea. Korean Society of Limnology 20:13-20.

Kim IS, Kim SY (1993) Interspecific hybridization between Oryzias sinensis and O. latipes from Korea. Korean Journal of Ichthyology 5:113-121.

Kim IS, Lee EH (1992) New record of the ricefish. Oryzias latipes sinensis (Pisces, Oryzidae) from Korea. The Korean Society of Systematic Zoology 8:177-182.

Kim IS, Moon KC (1987) The karyotype of a ricefish. Oryzias latipes from southern Korea. The Korean Society for Intergrative Biology 30:379-386.

Lee SH, Oh GN, Kim KS, Oh YS, Kang KW, Hwang JH, Lee BI, Lee WK and Han KH (2008) Embryonic and larval development of goby minnow, Pseudogobio esocinus. 
Development \& Reproduction 12(3):283-288.

Lee WO, Kim KH, Back JM and Song MY (2013) Egg development and early life history of Zacco koreanus (Pisces, Cyprinidae). Korean Journal of Ichthyology 25:200-207.

Levan A, Fredga K, Sandberg AA (1964) Nomenclature for centromeric position on chromosome. Hereditas 52:201-220.

Magtoon W, Uwa H (1985) Karyotype evolution and relationship of a small ricefish. Oryzias minutillus. from Thailand. Proc Japan Acad 61:157-160.

Noh GE, Rho S, Min BH and Chang YJ (2011) Egg development and effects of livefood and thyroid hormone on the Amphiprion melanopus larvae. Development \& Reproduction 15:121-131.

Okiyama M (1979) Manuals for the larval fish taxonomy (2), General aspects of larval characters that aid identification 2:53-59.

Park CK, Yeon IH, Choi NH, Han KH and Lee WK (2008)
Egg development and morphology of larva and juvenile of the chub mackerel, Scomber japonicus. Development \& Reproduction 12:207-213.

Russell FS (1976) The eggs and planktonic stages of Brithsh marine fishes. Academic Press, Inc., London. pp. 524.

Uwa H (1986) Karyotype evolution and geographical distribution in the ricefish genus Oryzias. Indo - Pacific fish biology: Proceedings of the second International conference on Indo - Pacific Fishes. edited by T. Ueno. R. Arai. T. Taniuchi and K. Matsuura. 1986:867-876.

Uwa HG, Jeon SR (1987) Karyotypes in two divergent groups of a ricefish Oryzias latipes from Korea. Korean Society of Limnology 20:139-147.

Yun SM, Han KH, Lee SH, Yim HS, Hwang JH, Yeon IH and Kim YC (2011) Embryonic and larva development of nake-headed goby, Luciogobius grandis. Development \& Reproduction 12:133-139. 